\title{
Effect of Fun Factors on Self-Efficacy and Quality of Life in Hair Designers
}

\author{
Young-jo Lee \\ Department of Hair Beauty Course, Kyung-In Women's University, Incheon, Korea
}

Corresponding author: Young-jo Lee, Department of Hair Beauty Course, KyungIn Women's University, 63, Gyeyangsan-ro, Gyeyang-gu, Incheon 21041, Korea

Tel.: +82 329400114

Email: leewha88@naver.com

Received July 30, 2020

Revised October 27, 2020

Accepted December 10, 2020

Published December 30, 2020

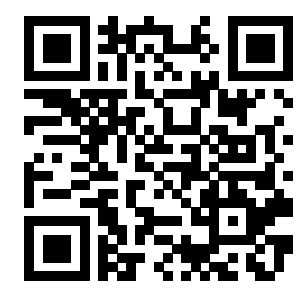

\begin{abstract}
Purpose: The purpose of this study is to identify the fun factors of hair designers to recover the sense of self-loss from heavy work, and to provide them as basic data for improving self-efficacy and quality of life, and personal competency. Methods: From July 1 to July 21, 2020, a three-week survey was conducted for beauty service workers in Seoul and Gyeonggi Province, and a total of 344 copies were used for analysis. The SPSS 26.0 program was used as the analysis method, and frequency analysis, factor analysis, reliability analysis, correlation analysis, one-way variance analysis, post-test, and multiple regression analysis were performed. Results: First, as a result of analyzing fun factors according to age, it was higher in the 50 s or older than in 20s, 30s, and 40s, and statistically significant differences were found in enjoyment, socializing, and health. Second, the effect of the hair designer's fun factor on self-efficacy and quality of life showed a statistically positive (+) correlation, and the mental well-being of the quality of life had a negative (-) correlation. Third, the influence of the fun factor on self-efficacy showed a statistically significant positive $(+)$ correlation in pleasure, health, and self-efficacy. Fourth, the effect of self-efficacy on the quality of life showed a statistically significant positive (+) correlation in physical well-being and competence. Conclusions: This study was conducted to establish the relationship between the self-efficacy of hair designer on the quality of life, and the older the hair designer, the more interesting the fun factors. The enjoyment and health of the fun factor influenced physical well-being and competence, resulting in a result that helped improve the quality of life.
\end{abstract}

Keywords: Hair designer, Fun factors, Self-efficacy, Quality of life, Self-satisfaction

\section{Introduction}

헤어 디자인은 조형 예술이다. 창의적인 예술적 가치는 시간, 돈, 노력으로 이루어지는 지식재산이고 경제를 움직이며 나라의 재산이 기에 미용예술인의 소중한 지적재산권은 보호되어야 한다. 이렇듯 헤어 디자이너의 예술적 가치는 4 차산업과도 맥을 같이한다.

뷰티 산업은 이용, 미용업에 관련된 서비스산업으로 화장품 및 관 련된 모든 기기 제조개발 향상을 위한 산업으로 신체를 건강하고 아 름답게 유지 관리하는데 필요한 재료, 물품 및 서비스에 관련된 산업 이며, 고부가 가치를 창출할 수 있는 미래 먹 걸이 산업이기에 업체 들 간에 경쟁이 치열하다(Kim, 2019). 치열한 경쟁 속에서 고부가가 치를 창출하는 헤어 디자이너가 재미있고 행복하다. 하지만 헤어 디 자이너의 서비스현장은 지나친 고객서비스의 질과 고객만족도를 높
이기 위해 과도한 고객중심을 지향하게 된다(Lim \& Kim, 2016). 따 라서 과중한 업무스트레스와 매출압박에 시달리게 되고 때로는 고 객에게 성희롱 적인 말과 행동으로 직업에 대한 상실감을 직면하기 도 한다. 헤어 디자이너는 업무 특정상 고객기대에 부응하기 위해 육 체적 정신적 압박감을 고객 및 동료와 상사와의 관계에서 오게 되고, 열악한 근무환경, 저임금 및 복리후생으로 인해 직무에 대한 회의를 느끼게 된다(Lee, 2020). 뷰티 살롱들은 대부분 소규모로 운영되기 에 인적자원 의존도가 높은 노동집약적인 미용분야에서 가장 필요한 것은 영세성과 비효율적인 인적자원관리를 해결하고 업무의 유연성 을 적용함으로써 급변하는 시장경쟁에 경쟁력강화에 필요하다(Kim et al., 2017). 특히 인적자원관리는 기업의 성패를 가름하는 중요한 요소이고 조직을 효율적으로 운영하고 조직 환경에 대처할 수 있어 소통을 필요로 하는 서비스 산업에 중요한 요소이다(Park, 2018). 
$\mathrm{Kim}$ (2016)은 재미의 개념은 즐거움, 좋아함, 긍정적인 정서의 반 응이다고 하였고, Goo \& Kim (2016)은 무술수련의 재미요인은 성 취감 및 신체적, 심리적 건강과 수련만족이라고 하였다. 재미는 열정 이며 개인이 좋아하고 시간과 에너지를 투자할 만한 열정과 스스로 이끄는 힘이다. 열정은 강한 동기를 통한 성취감을 촉진시켜 목표를 달성하게 한다(Kim et al., 2015). 목표를 달성하기 위해서는 열정이 있어야 하기에 상관관계를 형성한다.

Ahn \& Park (2019)은 개인과 공중의 위생을 중요시하는 미용계 열의 대학생들이 손을 청결히 하는 행위로 자기 효능감이 높아졌다. 성공적으로 목표달성을 위한 자기 효능감은 자신감에서 오고 개인의 인지적 전략이며, 건강증진과 자아실현을 향상시킨다(Choi \& Yoo, 2011). Han \& Kim (2019)은 여성들은 간단한 헤어 연출과 이미지 메이킹을 통하여 전체적인 조화를 이룰 때 긍정적인 자기 효능감을 높인다고 하였다.

삶의 질의 개념적 정의는 개인의 실제 활동, 습관이나 생활습관, 직업능력, 창조능력이다(Hornquist, 1990). 삶은 풍요롭고 안전한 삶을 위해 끈임 없는 노력과 도전의 연속적이며, 뷰티 종사자의 안 락한 삶을 지향하기 위한 필요한 것이 무엇일까 생각해본다면 보다 나은 삶을 살기 위한 노력 일 것이다. 삶의 질은 주관적 요소로 개인 마다 행복감과 만족감은 다르게 느껴지지만 삶의 목표를 향해 노력 하는 것이고 풍요에서 오는 정신적 만족감일 것이다. Rhee (2017), Kim et al. (2019), Kim \& Ji (2019), Lee (2017) 등 연구는 근무환 경으로 인하여 삶의 질에 영향을 미친다고 하였다. 이처럼 미용인의 삶의 질에 관한 연구는 있지만 헤어 디자인의 재미요인에 대한 연구 는 전무하다. 따라서 본 연구의 목적은 헤어 디자이너의 재미요인이 자기 효능감과 삶의 질에 어떤 영향을 미치는지를 규명하고자 한다.

\section{Methods}

\section{1.연구대상자 및 절차}

본 연구는 2020년 7월1일부터 2020년 7월21일까지 3주간 설문 조사를 실시하여 데이터를 수집하였다. 연구대상은 서울, 경기지 역의 헤어 디자이너를 대상으로 하여 344 부를 분석에 사용하였다.

\section{2. 측정도구}

본 연구의 설문문항은 정확한 분석을 위해 선행연구를 바탕으로 하였으며, 헤어 디자이너의 일반적특성 3 문항, 재미요인 15 문항을 사용하였다. Baek et al. (2015)가 제시한 자기 효능감을 수정 보 완하여 10 문항, 삶의 질 15 문항을 사용하였다. 인구 통계학적 정 보를 포함하여 총 43 문항으로 구성하였다.

\section{3. 분석방법}

본 연구에 수집된 자료는 SPSS프로그램 26.0 (IBM, USA)을 이용하여 처리하였다. 분석방법으로 연구대상자의 인구학적 특성 을 살펴보기 위해 빈도분석을 실시하였고, 측정도구의 타당도와 신뢰도 검증을 위해 요인분석과 신뢰도분석(Cronbach's $\alpha$ )을 실시 하였다. 연령에 따른 헤어 디자이너의 평균 차이 분석을 위해 일원 분산분석(One-way ANOVA)과 사후검증(Scheffe's)을 실시하였 고, 재미요인이 자기효능감, 삶의 질의 상관관계를 분석하였으며, 헤어 디자이너의 재미요인이 자기 효능감, 삶의 질에 미치는 영향 을 살펴보기 위해 다중회귀분석(multi-regression)을 실시하였 다.

Table 1. General characteristics

\begin{tabular}{|c|c|c|c|}
\hline Factor & & $\mathrm{N}$ & Percentage (\%) \\
\hline \multirow{4}{*}{ Age (year) } & $20 \mathrm{~s}$ & 160 & 46.5 \\
\hline & $30 \mathrm{~s}$ & 64 & 18.6 \\
\hline & $40 s$ & 65 & 18.8 \\
\hline & 50 s or older & 55 & 15.9 \\
\hline \multirow{4}{*}{ Position } & Assistant & 90 & 26.1 \\
\hline & Hair stylist & 97 & 28.1 \\
\hline & Supervisor & 68 & 19.7 \\
\hline & Manger & 89 & 25.8 \\
\hline \multirow{6}{*}{ Service life } & Not more than 1 year & 75 & 21.8 \\
\hline & $1-5$ years & 97 & 28.1 \\
\hline & $5-10$ years & 68 & 19.7 \\
\hline & $10-15$ years & 15 & 4.3 \\
\hline & More than 15 years & 89 & 25.8 \\
\hline & Total & 344 & 100.0 \\
\hline
\end{tabular}




\section{Results}

본 연구는 헤어 디자이너의 재미요인이 자기 효능감 및 삶의 질에 미치는 영향을 살펴본 것으로 표본은 헤어 미용에 종사하고 있는 총 344 명을 대상으로 하였다.

\section{1. 조사대상자의 일반적 특성}

조사대상의 일반적 특성은 Table 1 와 같다. 표본은 헤어 미용 에 종사하고 있는 총 344 명을 대상으로 하였다. 연령은 20 대 160 명(46.5\%), 30대 64명(18.6\%), 40대 65명(18.8\%), 50대이상 55명 $(15.9 \%)$ 으로 조사되어 20 대가 가장 많은 것으로 나타났다. 직급은 보조급 90명(26.1\%), 일반급 97명(28.1\%). 관리자급 68명(19.7\%), 원장급 89 명(25.8\%)으로 일반급이 가장 많은 것으로 나타났다. 근무 년수는 1년미만 75 명(25.1\%), 1년이상-5년미만 97명(28.1\%), 5년 이상-10년미만 69명(19.7\%), 10년이상-15년미만 15명(4.3\%), 15 년이상 89 명 $(25.8 \%)$ 로 조사되어 1년이상-5년미만에서 가장 많은 것으로 나타났다.

\section{2. 측정도구의 타당도 및 신뢰도}

재미요인 측정도구의 타당성 검증을 위해요인 추출방법은 주성
분 분석(principle component analysis)을 진행했으며, 요인적재 치의 단순화를 위해 회전방법은 직각회전인 베리맥스(varimax) 방 식을 사용하였다. 요인적재량(factor loading)은 0.05 이상인 경우 유효하게 적용하였으며 각 변수들 간의 상관관계를 살펴보기 위해 Bartlett의 구성형 검증을 하였다. 또한 변수들 간의 적합성 확인을 위해 Kaiser-Meyer-Olkin (KMO) 지수를 산출하였다. 재미요인의 측정도구의 타당성을 검증하고자 요인분석을 실시한 결과(Table 2), 재미요인 15 문항은 4 개의 요인으로 추출되었으며, 자기효능감 10 문 항, 삶의 질 15 문항 4 개의 하위요인으로 구성되었다. $\mathrm{KMO}$ 지수는 0.843 로 표본의 적합성이 확인되었으며, Bartlett 구성형 검증치는

$\chi^{2}=1379.698, p<0.001$ 으로 변수 간의 상관이 선형적 관계임이 확 인되었고 전체 변량(total variance)은 $52.29 \%$ 의 설명력을 보였다. 재미요인 분석에 적합함이 확인된 4 개의 요인은 즐거움, 사교, 성취 감, 건강으로 하위요인의 신뢰도(Cronbach's $\alpha$ ) 값은 0.839 으로 나 타났으며 통계적 수용 가능한 내적일치도를 보였다.

자기 효능감의 요인적재량은 0.05 이상인 경우 유효하게 적용하 였으며 각 변수들 간의 상관관계를 살펴보기 위해 Bartlett의 구성형 검증을 하였다. 또한 변수들 간의 적합성 확인을 위해 $\mathrm{KMO}$ 지수를 산출하였다. 자기 효능감의 측정도구의 타당성을 검증하고자 요인

Table 2. Fun factors feasibility

\begin{tabular}{|c|c|c|c|c|c|c|}
\hline \multirow{2}{*}{ Factors } & & \multicolumn{4}{|c|}{ Components } & \multirow{2}{*}{ Communality } \\
\hline & & 1 & 2 & 3 & 4 & \\
\hline \multirow{7}{*}{ Enjoyment } & Question6 & 0.745 & & & & 0.620 \\
\hline & Question4 & 0.720 & & & & 0.584 \\
\hline & Question3 & 0.703 & & & & 0.637 \\
\hline & Question5 & 0.690 & & & & 0.596 \\
\hline & Question1 & 0.599 & & & & 0.515 \\
\hline & Question8 & 0.561 & & & & 0.427 \\
\hline & Question9 & 0.548 & & & & 0.527 \\
\hline \multirow{3}{*}{ Social intercourse } & Question7 & & 0.761 & & & 0.636 \\
\hline & Question10 & & 0.633 & & & 0.549 \\
\hline & Question11 & & 0.577 & & & 0.584 \\
\hline \multirow{2}{*}{ Sense of accomplishment } & Question12 & & & 0.724 & & 0.650 \\
\hline & Question13 & & & 0.674 & & 0.536 \\
\hline \multirow{3}{*}{ Health } & Question16 & & & & 0.698 & 0.540 \\
\hline & Question14 & & & & 0.627 & 0.536 \\
\hline & Question15 & & & & 0.519 & 0.506 \\
\hline Eigen value & & 31.417 & 10.260 & 7.868 & 6.743 & \\
\hline Variance (\%) & & 31.417 & 10.260 & 7.868 & 6.743 & \\
\hline Cumulative (\%) & & 31.417 & 41.677 & 49.545 & 56.288 & \\
\hline Cronbach's $\alpha$ & & 0.834 & 0.603 & 0.537 & 0.481 & \\
\hline Total Cronbach's $\alpha$ & & & 0.839 & & & \\
\hline
\end{tabular}

$\mathrm{KMO}=0.843 ; \chi^{2}=1379.698 ; p<0.001$. 
Effect of Fun Factors on Self-Efficacy and Quality of Life in Hair Designers

분석을 실시한 결과(Table 3), $\mathrm{KMO}$ 지수는 0.888 로 표본의 적합성

으로 변수 간의 상관이 선형적 관계임이 확인되었고 전체 변량(total

이 확인되었으며, Bartlett 구성형 검증치는 $\chi^{2}=865.414, p<0.001$ variance)은 $39.69 \%$ 의 설명력을 보였다. 자기효능감 하위요인의 신

Table 3. Feasibility of self-efficacy

\begin{tabular}{|c|c|c|c|}
\hline \multirow{2}{*}{ Factors } & & Component & \multirow{2}{*}{ Communality } \\
\hline & & 1 & \\
\hline \multirow{10}{*}{ Self-efficacy } & Question4 & 0.714 & 0.510 \\
\hline & Question7 & 0.696 & 0.484 \\
\hline & Question9 & 0.687 & 0.473 \\
\hline & Question8 & 0.684 & 0.468 \\
\hline & Question3 & 0.669 & 0.448 \\
\hline & Question2 & 0.666 & 0.444 \\
\hline & Question10 & 0.646 & 0.417 \\
\hline & Question5 & 0.645 & 0.415 \\
\hline & Question1 & 0.469 & 0.220 \\
\hline & Question6 & 0.303 & 0.092 \\
\hline Eigen value & & 39.695 & \\
\hline Variance (\%) & & 39.695 & \\
\hline Cumulative (\%) & & 39.695 & \\
\hline Cronbach's $\alpha$ & & 0.741 & \\
\hline
\end{tabular}

Table 4. Quality of life feasibility

\begin{tabular}{|c|c|c|c|c|c|c|}
\hline \multirow{2}{*}{ Factors } & & \multicolumn{4}{|c|}{ Components } & \multirow{2}{*}{ Communalit } \\
\hline & & 1 & 2 & 3 & 4 & \\
\hline \multirow{6}{*}{$\mathrm{PH}$} & Question3 & 0.758 & & & & 0.590 \\
\hline & Question6 & 0.699 & & & & 0.574 \\
\hline & Question2 & 0.608 & & & & 0.424 \\
\hline & Question9 & 0.598 & & & & 0.458 \\
\hline & Question5 & 0.592 & & & & 0.476 \\
\hline & Question7 & 0.551 & & & & 0.337 \\
\hline \multirow{4}{*}{ MT } & Question23 & & 0.755 & & & 0.584 \\
\hline & Question21 & & 0.732 & & & 0.603 \\
\hline & Question22 & & 0.666 & & & 0.598 \\
\hline & Question20 & & 0.604 & & & 0.388 \\
\hline \multirow{3}{*}{ C } & Question19 & & & 0.665 & & 0.463 \\
\hline & 0.618 & & & 0.633 & & 0.442 \\
\hline & Question14 & & & 0.516 & & 0.495 \\
\hline \multirow{2}{*}{ S } & Question11 & & & & 0.627 & 0.687 \\
\hline & Question12 & & & & 0.519 & 0.570 \\
\hline Eigen value & & 22.163 & 13.865 & 7.883 & 7.168 & \\
\hline Variance (\%) & & 22.163 & 13.865 & 7.883 & 7.168 & \\
\hline Cumulative (\%) & & 22.163 & 36.028 & 43.911 & 51.079 & \\
\hline Cronbach's $\alpha$ & & 0.735 & 0.675 & 0.474 & 0.096 & \\
\hline Total Cronbach's $\alpha$ & & & 0.614 & & & \\
\hline
\end{tabular}

$\mathrm{KMO}=0.788, \chi^{2}=879.991, p<0.001 ; \mathrm{PH}$, physical well-being; $\mathrm{MT}$, mental well-being; C, competence; $\mathrm{S}$, stability. 
뢰도(Cronbach's $\alpha$ ) 값은 0.741으로 나타났으며 통계적 수용 가능한 내적일치도를 보였다.

삶의 질 측정도구의 타당성 검증을 위해요인 추출방법은 주성분 분석이며, 요인적재치의 단순화를 위해 회전방법은 직각회전인 베 리맥스(varimax) 방식을 사용하였다. 요인적재량은 0.05 이상인 경 우 유효하게 적용하였으며 각 변수들 간의 상관관계를 살펴보기 위 해 Bartlett의 구성형 검증을 하였다. 또한 변수들 간의 적합성 확 인을 위해 $\mathrm{KMO}$ 지수를 산출하였다. 재미요인의 측정도구의 타당 성을 검증하고자 요인분석을 실시한 결과(Table 4), $\mathrm{KMO}$ 지수는 0.788 로 표본의 적합성이 확인되었으며, Bartlett 구성형 검증치는

$\chi^{2}=879.991, p<0.001$ 으로 변수 간의 상관이 선형적 관계임이 확 인되었고 전체 변량(total variance)은 $51.08 \%$ 의 설명력을 보였다.
삶의 질의분석에 적합함이 확인된 4 개의 요인은 신체적 안녕, 정신 적 안녕, 유능감, 안정성으로 하위요인의 신뢰도(Cronbach's $\alpha$ ) 값은 0.614 으로 나타났으며 통계적 수용 가능한 내적일치도를 보였다.

\section{2. 연령에 따른 재미요인의 평균의 차이분석}

연령에 따른 헤어 디자이너의 재미요인(즐거움, 사교, 성취감, 건 강)의 평균차이를 분석을 위한 일원분산분석(One-way ANOVA) 결 과는 Table 5 와 같이 나타났다. 헤어 디자이너의 재미요인 하위 요 인의 평균 차이를 분석한 결과, 즐거움 $(F=17.615, p<0.001)$, 사교 $(F=5.513, p\langle 0.01)$, 성취감 $(F=1.1812, p>0.05)$, 건강 $(F=10.163$, $p<0.001$ )에서 즐거움, 사교, 건강은 집단 간 통계적 유의한 차이를 보였다. 이에 사후분석(Scheffe's)을 실시한 결과 4집단 모두 20대, 30 대, 40 대집단 보다 50 대 이상 집단이 더 높은 평균치를 보였다.

Table 5. Differences in the average of the fun factors by age

\begin{tabular}{|c|c|c|c|c|c|c|c|c|}
\hline \multicolumn{2}{|l|}{ Classification } & Age & $\mathrm{N}$ & $M$ & SD & $F$ & $p$ & Post-hoc \\
\hline \multirow{16}{*}{ Fun factors } & \multirow{4}{*}{$E$} & $20 s^{A)}$ & 160 & 3.57 & 0.62278 & \multirow{4}{*}{17.615} & \multirow{4}{*}{0.000} & \multirow{4}{*}{$A, B, C<D$} \\
\hline & & $30 s^{B)}$ & 64 & 3.56 & 3.5647 & & & \\
\hline & & $40 s^{c)}$ & 65 & 3.50 & 0.73241 & & & \\
\hline & & $50 \mathrm{~s}$ or order ${ }^{\mathrm{D})}$ & 55 & 4.19 & 0.49439 & & & \\
\hline & \multirow{4}{*}{$\mathrm{SI}$} & $20 s^{A)}$ & 160 & 3.8625 & 0.53185 & \multirow{4}{*}{5.513} & \multirow{4}{*}{0.001} & \multirow{4}{*}{$A, B, C<D$} \\
\hline & & $30 s^{B)}$ & 64 & 3.8385 & 0.55075 & & & \\
\hline & & $40 s^{())}$ & 65 & 3.6564 & 0.70457 & & & \\
\hline & & 50 s or order ${ }^{D)}$ & 55 & 4.0788 & 0.50903 & & & \\
\hline & \multirow{4}{*}{ SE } & $20 s^{A)}$ & 160 & 3.9625 & 0.52170 & \multirow{4}{*}{1.1812} & \multirow{4}{*}{0.145} & \multirow{4}{*}{$A, B, C<D$} \\
\hline & & $30 v^{B)}$ & 64 & 3.8438 & 0.60340 & & & \\
\hline & & $40 s^{\mathrm{C})}$ & 65 & 3.8154 & 0.72656 & & & \\
\hline & & 50 s or order $^{\mathrm{D})}$ & 55 & 4.0182 & 0.59289 & & & \\
\hline & \multirow{4}{*}{$\mathrm{H}$} & $20 s^{A)}$ & 160 & 3.6312 & 0.52418 & \multirow{4}{*}{10.163} & \multirow{4}{*}{0.000} & \multirow{4}{*}{$A, B, C<D$} \\
\hline & & $30 s^{B)}$ & 64 & 3.6927 & 0.47254 & & & \\
\hline & & $40 s^{()}$ & 65 & 3.7487 & 0.67964 & & & \\
\hline & & 50 s or order ${ }^{\mathrm{D})}$ & 55 & 4.1212 & 0.67392 & & & \\
\hline
\end{tabular}

${ }^{* *} p<0.01 ;{ }^{* * *} p<0.001 \mathrm{E}$, enjoyment; SI, social intercourse; SE, sense of accomplishment; H, health.

Table 6. Correlation analysis of fun factor, self-efficacy, quality of life

\begin{tabular}{|c|c|c|c|c|c|c|c|c|c|}
\hline & $E$ & $\mathrm{SI}$ & SE & $\mathrm{H}$ & SF & $\mathrm{PH}$ & MT & C & $\mathrm{S}$ \\
\hline $\mathrm{E}$ & 1 & & & & & & & & \\
\hline SI & $0.372^{* *}$ & 1 & & & & & & & \\
\hline SE & $0.270^{* *}$ & $0.701^{* *}$ & 1 & & & & & & \\
\hline $\mathrm{H}$ & $0.491^{* *}$ & $0.373^{* *}$ & $0.371^{* *}$ & 1 & & & & & \\
\hline SF & $0.559^{* *}$ & $0.284^{* *}$ & $0.279^{* *}$ & $0.452^{* *}$ & 1 & & & & \\
\hline $\mathrm{PH}$ & $0.414^{* *}$ & $0.241^{* *}$ & $0.228^{* *}$ & $0.330^{* *}$ & $0.509^{* *}$ & 1 & & & \\
\hline MT & -0.067 & -0.106 & -0.077 & -0.059 & $-0.129^{*}$ & $-0.196^{* *}$ & 1 & & \\
\hline C & $0.290^{* *}$ & $0.122^{*}$ & 0.048 & $0.249^{* *}$ & $0.292^{* *}$ & $0.403^{* *}$ & 0.023 & 1 & \\
\hline S & 0.047 & 0.051 & 0.057 & $0.137^{*}$ & 0.100 & 0.051 & $0.131^{*}$ & 0.045 & 1 \\
\hline
\end{tabular}

${ }^{*} p<0.05 ;{ }^{* *} p<0.01$. E, enjoyment; SI, social intercourse; SE, sense of accomplishment; $\mathrm{H}$, health; SF, self-efficacy; PH, physical well-being; MT, mental well-being; C, competence; S, stability. 


\section{3. 재미요인, 자기효능감, 삶의 질의 상관관계}

재미요인, 자기효능감 및 삶의 질의 상관관계를 분석한 결과 는 Table 6 과 같다. 재미요인 중 즐거움은 사교 $(\mathrm{r}=0.372)$, 성취 감 $(\mathrm{r}=0.270)$, 건강 $(\mathrm{r}=0.491)$, 자기효능감 $(\mathrm{r}=0.559)$, 신체적 안녕 $(\mathrm{r}=0.414)$, 유능감 $(\mathrm{r}=0.290)$, 안정성 $(\mathrm{r}=0.047)$ 은 통계학적 유의한 정적 $(+)$ 상관관계가 나타났으며, 정신적 안녕 $(\mathrm{r}=-0.067)$ 은 부적 $(-)$ 상관관계를 나타났다. 사교의 성취감 $(\mathrm{r}=0.701)$, 건강 $(\mathrm{r}=0.373)$, 자 기 효능감 $(\mathrm{r}=0.284)$, 신체적 안녕 $(\mathrm{r}=0.241)$, 유능감 $(\mathrm{r}=0.122)$, 안정 성 $(\mathrm{r}=0.051)$ 에서 통계학적 유의한 정적 $(+)$ 상관관계가 나타났고, 정 신적안녕 $(\mathrm{r}=-0.106)$ 은 부적 $(-)$ 상관관계가 나타났다. 성취감은 건강 $(\mathrm{r}=0.371)$, 자기효능감 $(\mathrm{r}=0.279)$, 신체적 안녕 $(\mathrm{r}=0.228)$, 유능감 $(\mathrm{r}=-$ $0.048)$, 안정성 $(\mathrm{r}=-0.057)$ 에서 통계학적 유의한 정적 $(+)$ 상관관계가 나타났고, 정신적 안녕 $(\mathrm{r}=-0.077)$ 은 부적(-)상관관계가 나타났다, 건 강은 자기효능감 $(\mathrm{r}=0.452)$, 신체적 안녕 $(\mathrm{r}=0.330)$, 유능감 $(\mathrm{r}=0.249)$, 안정성 $(\mathrm{r}=0.137)$ 에서 통계학적 유의한 정적( $(+)$ 상관관계가 나타났고, 정신적 안녕 $(\mathrm{r}=-0.059)$ 은 부적 $(-)$ 상관관계가 나타났다.

자기 효능감은 신체적 안녕 $(\mathrm{r}=0.509)$, 유능감 $(\mathrm{r}=0.292)$, 안정성 $(\mathrm{r}=0.100)$ 에서 통계학적 유의한 정적 $(+)$ 상관계가 나타났고, 정신적 안녕 $(r=-0.129)$ 부정상관관계가 나타났다. 삶의 질의 하위요인 신체 적 안녕은 유능감 $(\mathrm{r}=0.403)$, 안정성 $(\mathrm{r}=0.051)$ 에서 통계학적 유의한 정적(+)상관관계가 나타났고, 정신적 안녕 $(\mathrm{r}=-0.196)$ 은 부적(-)상관 관계가 나타났다. 정신적 안녕은 유능감 $(\mathrm{r}=0.023)$, 안정성 $(\mathrm{r}=0.131)$ 에서 통계학적 유의한 정적(+)상관관계가 나타났다. 유능감은 안정성 $(\mathrm{r}=0.0045)$ 에서 통계학적 유의한 정적 $(+)$ 상관관계가 나타났다.

\section{4. 재미요인이 자기 효능감에 미치는 영향}

재미요인이 자기 효능감에 미치는 영향을 규명하기 위해 Table 7 와 같이 다중회귀분석(multi-regression)을 진행하였다. 분석결과, Durbin-Watson 값은 1.570 으로 2에 가까워 변수들 간의 자기 상 관의 문제가 없이 독립적으로 나타났으며, 공차 $0.493-0.694$ 이였 으며, VIF 값은 1.400-2.124로 나타나 다중공선성의 문제가 없 는 것으로 나타났다. 재미요인이 자기 효능감에 미치는 영향을 분 석한 결과 독립변수와 종속변수 간의 상관계수(R)은 0.601 이였으 며 결정계수 $\left(\mathrm{R}^{2}\right)$ 가 0.353 로 나타나 독립변인이 종속변인에 미치는 설명력은 $35.3 \%$ 로 나타났다. 또한 회귀모형의 적합도 분산분석 결 과, $F=47.842, p<0.001$ 수준에서 통계적 유의하게 나타나 회귀식 이 적합함을 보여주고 있다. 자기효능감에 미치는 영향으로 즐거움 ( $\beta=0.444, t=8.556, p\langle 0.001)$, 사교( $\beta=0.031, t=-0.486, p\rangle 0.05)$, 성취감 $(\beta=0.105, t=1.691, p>0.05)$, 건강 $(\beta=0.209, t=4.012$, $p\langle 0.001)$ 으로 나타나, 즐거움, 건강은 자기 효능감에 통계적으로 유 의하게 정적(+) 영향을 미치고 있는 것으로 나타났다.

\section{5. 자기 효능감이 삶의 질에 미치는 영향}

자기 효능감이 삶의 질에 미치는 영향을 규명하기 위해 Table 8 와 같이 다중회귀분석을 진행했다. 분석결과, Durbin-Watson 값은 1.625 으로 2 에 가까워 변수들 간의 자기 상관의 문제가 없이 독립 적으로 나타났으며, 공차 $0.792-0.977$ 이였으며, VIF 값은 1.0241.264 로 나타나 다중공선성의 문제가 없는 것으로 나타났다. 자기 효능감이 삶의 질에 미치는 영향을 분석한 결과 독립변수와 종속변 수 간의 상관계수(R)은 0.525 이였으며 결정계수 $\left(\mathrm{R}^{2}\right)$ 가 0.267 로 나

Table 7. Effects of fun factors on self-efficacy

\begin{tabular}{llccccccc}
\hline $\begin{array}{l}\text { Dependent } \\
\text { variable }\end{array}$ & $\begin{array}{l}\text { Independent } \\
\text { variable }\end{array}$ & $\mathrm{B}$ & $\mathrm{SE}$ & $\beta$ & $\mathrm{T}$ & $p$ & Tolerancing & VIP \\
& (Constant) & 1.145 & 0.218 & & 5.244 & 0.000 & \\
Self-efficacy & $\mathrm{E}$ & 0.407 & 0.048 & 0.444 & 8.556 & 0.000 & 0.714 & 1.400 \\
& $\mathrm{SI}$ & -0.032 & 0.065 & 0.031 & -0.486 & 0.628 & 0.471 & 2.124 \\
& $\mathrm{SE}$ & 0.106 & 0.062 & 0.105 & 1.691 & 0.092 & 0.493 & 2.029 \\
& $\mathrm{H}$ & 0.210 & 0.052 & 0.209 & 4.012 & 0.000 & 0.694 & 1.440 \\
\hline
\end{tabular}

$\mathrm{R}=0.601^{\mathrm{a}}$, adj $\mathrm{R}^{2}=0.353, F=47.842 ; p<0.001$; Durbin-Watson=1.570; $\mathrm{E}$, enjoyment; $\mathrm{SI}$, social intercourse; $\mathrm{SE}$, sense of accomplishment; $\mathrm{H}$, health.

Table 8. Effect of self-efficacy on quality of life

\begin{tabular}{llccccccc}
\hline $\begin{array}{l}\text { Dependent } \\
\text { variable }\end{array}$ & $\begin{array}{l}\text { Independent } \\
\text { variable }\end{array}$ & $\mathrm{B}$ & $\mathrm{SE}$ & $\beta$ & $\mathrm{T}$ & $p$ & Tolerancing & VIP \\
& (Constant) & 1.890 & 0.244 & & 7.739 & 0.000 & \\
& $\mathrm{PH}$ & 0.413 & 0.048 & 0.451 & 8.674 & 0.000 & 0.791 & 1.264 \\
Self-efficacy & $\mathrm{MT}$ & -0.050 & 0.045 & -0.053 & -1.112 & 0.267 & 0.930 & 1.075 \\
& $\mathrm{C}$ & 0.105 & 0.050 & 0.108 & 2.126 & 0.034 & 0.826 & 1.210 \\
& $\mathrm{~S}$ & 0.074 & 0.044 & 0.079 & 1.693 & 0.091 & 0.977 & 1.024 \\
\hline
\end{tabular}

$\mathrm{R}=0.525$; adj $\mathrm{R}^{2}=0.267 ; F=32.255 ; p<0.001$; Durbin-Watson=1.625; $\mathrm{PH}$, physical well-being; MT, mental well-being; C, competence; S, stability. 
타나 독립변인이 종속변인에 미치는 설명력은 $26.7 \%$ 로 나타났다. 또한 회귀모형의 적합도 분산분석 결과 $F=32.255, p<0.001$ 수준 에서 통계적 유의하게 나타나 회귀식이 적합함을 보여주고 있다. 자 기 효능감에 미치는 영향으로 신체적 안녕( $\beta=0.451, t=-8.6746$, $\mathrm{p}\langle 0.001)$, 정신적 안녕 $(\beta=-0.053, t=-1.112, p>0.05)$, 유능감 $(\beta=0.108, t=2.126, p\langle 0.05)$, 안정성 $(\beta=0.079, t=1.693, p\rangle 0.05$ 에 미치는 영향으로 신체적 안녕, 유능감은 통계적으로 유의하게 정적 (+) 영향을 미치고 있는 것으로 나타났다.

\section{Discussion}

본 연구는 헤어 디자이너의 재미요인이 자기 효능감 및 삶의 질에 미치는 영향을 규명하는데 목적이 있다. 본 연구결과를 바탕으로 논 의는 다음과 같다. 연령에 따른 재미요인은 50 대이상에서 즐거움, 사교, 성취감, 건강에서 가장 높게 나타났다. 이는 연령이 높으면 재 미에 관심을 가지고 자기 만족감에 영향을 미치는 것으로 사료된다. Lee (2019)의 체육교양 수업은 연령이 낮을수록 재미가 자기 효능 감에 미치는 영향이 높게 나왔는데 운동에서 오는 재미요인과 직업 에서 오는 재미요인은 연령에 따라 차이를 보이는 것으로 사료된다. Kim \& Yoon (2020)은 성취감이 신체적 자기 효능감에 가장 큰 영 향을 미치는 것은 운동에서 오는 재미요인과 본 연구에서 오는 재미 는 다르기 때문이다. Oh (2019)은 재미는 신체적, 심리적인 요인이 자기 효능감을 높여 필라테스 운동을 지속적으로 할 수 있게 한다. Yun et al. (2011)은 스노보드 참가자의 재미요인의 체력향상, 건강, 상호작용이 체력을 향상시켜 자부심과 성취감을 느끼게 하고 다양 한 연령과 어울리며 사교성을 증진시키고 대자연 속에서 즐거움으 로 삶을 쾌적하게 해준다고 하며 본 연구에서도 즐거움, 건강의 재 미요인이 신체적인 유능감을 주는 것으로 보아 본 연구 결과를 지지 해 주고 있다.

댄스스포츠 운동은 재미 있으며 심리적 행복감과 삶의 질이 높아 진다(Kang et al., 2018). 여가만족에서 오는 즐거움은 신체적 스트 레스가 없어져 몸과 마음이 가벼워지며, 자신감 획득에 기회가 되고 재미를 느끼는 상태는 풍요로움과 성취감 및 행복감을 주며 여성의 삶의 질 향상에 도움을 준다(Sa et al., 2017). 자기 효능감과 삶에 질에 관한 연구 Shin et al. (2014)은 자기 효능조절감은 업무를 수 행하는데 있어 자기관찰, 판단 반응을 잘 사용할 수 있어 업무의 성 취감과 관련이 있고 자기 효능감이 높아져 업무에 만족감과 삶의 질 향상이 높다고 하였다. Kim \& Yoon (2012)와 Kim \& Oh (2017)은 자기효능감 중에 자신감을 높일수록 주관적인 삶의 질 및 객관적인 삶의 질이 높아진다. 이러한 선행연구들은 본 연구결과의 재미요인 이 자기 효능감의 영향관계를 정적으로 뒷받침해준다. 따라서 헤어 디자이너의 즐거움, 건강은 신체적 안녕과 유능감을 주어 삶의 질을 향상시키는데 결정적인 요인으로 작용한다.

\section{Conclusion}

본 연구는 헤어 디자이너의 자기 효능감이 삶의 질에 미치는 영 향관계를 규명하기 위해 진행되었고 다음과 같은 연구결과를 도출 하였다. 헤어 디자이너는 연령이 높을수록 재미요인에 영향을 주었 다. 재미요인의 즐거움과 건강은, 신체적 안녕 및 유능감에 영향을 미쳐 삶의 질 향상에 도움을 주는 결과를 도출하였다. 본 연구의 제 한 점은 뷰티 종사자의 재미요인을 찾지 못하여 스포츠현장에서 나 오는 재미요인을 재구성하여 사용하였으며, 미래의 연구는 뷰티 현 실에 부합할 수 있는 질문지를 구성하는 것이 시급한 현실이며, 향 후 더 많은 뷰티 현장의 재미요인에 관한 연구가 필요할 것으로 사 료된다.

\section{Author's contribution}

YJL designed, performed experiments, analyzed data, and wrote the manuscript.

\section{Author details}

Young-jo Lee (Lecture), Department of Hair Beauty Course, Kyung-In Women's University, 63, Gyeyangsanro, Gyeyang-gu, Incheon 21041, Korea.

\section{References}

Ahn MJ, Park SJ. Mediation effect of self-efficacy on the relationship between knowledge of and compliance with handwashing in cosmetology students. Asian Journal of Beauty and Cosmetology, 17: 277-286, 2019.

Baek YA, Jung Y, Yoo TS. The corelation between of cosmetology worker's self efficacy, professional ethics, and job satisfaction with customer orientation. Journal of Korea Design Forum, 49: 229-242, 2015.

Choi HJ, Yoo JH. The effect of depression and self-efficacy on health promotion behavior among the elderly living alone in rural area. Journal of East-West Nursing Research, 17: 149-155, 2011.

Goo KB, Kim HR. Relationship between martial arts the enjoyment factor on the training satisfaction and retraining intention. The Korea Journal of Sports Science, 25: 795-807, 2016.

Han MS, Kim YS. Awareness of images of women aged 20-50 years and sense of self-effectiveness through production of hair images. Asian Journal of Beauty and 
Cosmetology, 17: 511-520, 2019.

Yun TJ, Kim YY, Shin SS. The effect of snowboard participants' enjoyment factors on psychological well-being and quality of life. Journal of Wellness, 6: 13-23, 2011.

Hornquist JO. Quality of life: concept and assessment. Scandinavian Journal of Social Medicine, 18: 69-79, 1989

Kang SB, Jang JY, Kim CS, Jeong SH. The effects of leisure attitude and fun factor on the psychological wellbeing and quality of life in dance sports participants of university. The Korean Journal of Sports Science, 27: 439-452, 2018.

Kim HJ, Ji JH. Effect of job stress of beauty industry employees on organizational citizenship behavior and quality of life. Journal of Investigative Cosmetology, 15: 305-313, 2019.

Kim HK, Yoon SY. Moderating effects of physical self-efficacy on the relation between soccer club members' fun factors and exercise emersion. Journal of Wellness, 15: 425-436, 2020.

Kim KH, Youn YH, Park EJ. The impact of wellness on the quality of life of beauticians. Journal of the Korean Society of Cosmetology, 25: 1100-1108, 2019.

Kim JH, Seo HS, Lee EH. The effect of human resource management on the organizational commitment of the beauty industry professionals. Journal of the Korean Society of Design Culture, 23: 223-234, 2017.

Kim JS. The relation among the sport amusement factor, leisure satisfaction and exercise persist of participants in tennis: a holistic perspective. Journal of Holistic Convergence Education, 20: 97-115, 2016.

Kim MJ. Structural relationships among cosmetologists' perceptions of achievement goal orientation, cosmetology industry growth potential \& importance of convergence industry and importance of personal competency. Journal of the Korean Society of Beauty and Art, 20: 159-178, 2019.

Kim SE, Oh SY. The impact of transformational leadership on self-efficacy and job satisfaction of beauty service providers. Journal of the Korean Society of Beauty and Art, 18: 47-60, 2017.

Kim SS, Yoon Ys. Effects of social support on self-efficacy and quality of life of Korean middle school children. Journal of Enneagram Studies, 9: 155-174, 2012.

Kim WK, Lee JW, Lee YI. The mediating effect of the fun factor in the relationship between the passion and psychological happiness of the college students participating in the cultural dance sports class. Journal of Korean Dance, 33: 1-23, 2015.

Lee $\mathrm{CH}$. Effect of sports physical enjoyment and physical selfefficacy in college student's of the physical education class participation. The Korean Journal of Sports, 17: 689-697, 2019.

Lee YC. The Effect of entertainment factor for housewives' dance sports participation on psychological well-being and emotional intelligence. Journal of Sport and Leisure Studies, 69: 295-307, 2017.

Lee YL. The correlation research of positive psychological capital and job stress in beauty related experts. Journal of the Korean Society of Beauty and Art, 21:31-45, 2020.

Lim SH, Kim YM. Effects of the beauty industry worker's communiction styles on rapport and customer satisfaction. Asia-pacific Journal of Multimedia Services Convergent with Art, Humanities, and Sociology, 6: 383395, 2016.

Oh HO. A study on influence of fun factors in pilates reformer exercise on self-efficacy and adherence intention index. The Korean Journal of Sports Science, 28: 209-224, 2019.

Park SJ. Mediating effects of organizational commitment on the relationship between beauty industry managers' leadership and customer orientation. Asian Journal of Beauty and Cosmetology, 16: 255-265, 2018.

Rhee YJ. Study on working environment of hair industry workers: focus on their quality of life. Journal of Investigative Cosmetology, 13: 173-182, 2017.

Shin SO, Roh ES, Kim ES. Caregiver's of the correlation between self-efficacy and quality of life. Journal of Korea Entertainment Industry Association, 8: 85-91, 2014.

Sa HJ, Lee CW, Kim MJ. The relationship among fun factor, leisure satisfaction and quality of life for female active senior. Journal of Korean Physical Education Association for Girls and Women, 31: 93-108, 2017. 


\section{국문초록}

\section{헤어 디자이너의 재미요인이 자기효능감 및 삶의 질에 미치는 영향}

이영조

경인여자대학교 헤어뷰티학과, 인천, 한국

목적: 본 연구는 헤어 디자이너의 재미요인을 파악하여 과중한 업무에서 오는 자기상실감 회복을 위하고, 자기효능감 및 삶의 질 향 상 및 개인역량강화에 기초자료로 제공하고자 한다. 방법: 서울, 경기지역의 뷰티 서비스업 종사자를 대상으로 2020년 7월 1일부터 7 월21일까지 3주간 설문조사를 하였고, 총 344부를 분석에 사용하였다. 분석방법은 SPSS 26.0 프로그램을 사용하여 빈도분석, 요 인분석, 신뢰도분석, 상관관계분석, 일원분산분석, 사후검증, 다중회귀분석을 수행하였다. 결과: 첫째, 연령에 따른 재미요인을 분 석한 결과 20 대, 30 대, 40 대보다 50 대 이상에서 더 높게 나타났으며, 즐거움, 사교, 건강에서 통계학적 유의한 차이가 나타났다. 둘 째, 헤어 디자이너의 재미요인이 자기효능감 및 삶의 질에 미치는 영향은 통계학적 정적(+) 상관관계를 보였고, 삶의 질의 정신적 안녕은 부적(-)상관관계가 나타났다. 셋째, 재미요인이 자기 효능감에 미치는 영향은 즐거움, 건강, 자기 효능감에서 통계학적으로 유의한 정적 $(+)$ 상관관계를 보였다. 넷째, 자기 효능감이 삶에 질에 미치는 영향은 신체적 안녕과 유능감이 통계학적으로 유의하게 정적(+)상관관계가 나타났다. 결론: 본 연구를 통해 헤어 디자이너의 자기 효능감이 삶의 질에 미치는 영향관계를 규명하기 위해 진 행되었으며, 헤어 디자이너의 연령이 높을수록 재미요인에 영향을 주었다. 재미요인의 즐거움과 건강은, 신체적 안녕 및 유능감에 영향을 미쳐 삶의 질향상에 도움을 주는 결과를 도출하였다.

핵심어: 헤어 디자이너, 재미요인, 자기효능감, 삶의 질, 자기만족감

\section{참고문헌}

강신범, 장재용, 김창숙, 정상훈. 대학교양 댄스스포츠 참가자의 여가태도와 재미요인이 심리적행복감과 삶의 질에 미치는

영향. 한국체육학회지, 27: 439-452, 2018.

구강본, 김화룡. 무술수련의 재미요인과 수련만족 및 재 수련의도의 관계. 한국체육과학회지, 25: 795-807, 2016.

김경희, 윤영한, 박은준. 미용종사자의 웰니스가 삶의 질에 미치는 영향. 한국미용학회지, 25: 1100-1108, 2019.

김성숙, 윤운성. 중학생의 사회적지지가 자기효능감과 삶의 질에 미치는 영향. 에니어그램연구, 9: 155-174, 2012.

김민정. 뷰티 산업 종사자의 성취목표지향성 및 뷰티 산업 발전가능성, 융복합 산업중요도, 개인역량 중요도 인식 간의 구

조관계연구. 한국인체미용예술학회지, 20: 159-178, 2019.

김세은, 오수연. 변혁적 리더십이 미용종사자의 자기 효능감과 직무만족에 미치는 영향. 한국인체예술학회지, 18: 47-60,

2017.

김우경, 이준우, 이영일. 교양 댄스스포츠 참여 대학생의 열정과 심리적 행복감과의 관계: 재미요인의 매개효과. 한국무용

연구, 33: 1-23, 2015.

김지수. 스포츠 재미요인과 여가만족 및 운동지속의 관계: 홀리스틱 교육의 관점에서. 홀리스틱교육연구, 20: 97-115,

2016.

김지현, 서현숙, 이은희. 뷰티산업종사자의 인적자원관리가 조직몰입에 미치는 영향. 한국디자인문화학회지, 23: 223-

$234,2017$.

김학권, 윤상영. 축구동호회 회원의 재미요인과 운동몰입의 관계에서 신체적 자기효능감의 조절효과. 한국웰리스학회지, 15: 425-436, 2020.

김혜지, 지정훈. 미용 종사자의 직무스트레스가 조직시민행동과 삶의 질에 미치는 영향. 대한미용학회지, 15: 305-313, 2019. 
박선주. 미용산업 경영자의 리더십과 고객지향성 관계에 대한 조직몰입의 매개효과. 아시안뷰티화장품학술지, 16: 255$265,2018$.

백영애, 정연, 유태순. 미용서비스산업 종사자의 자기효능감, 직업윤리, 직무만족과 고객지향성 간의 관계. 한국디자인포 럼, 49: 229-242, 2015.

사혜지, 이철원, 김민정. 여가 활동에 참여하는 액티브 시니어 여성의 재미, 여가 만족 및 삶의 질의 구조적 관계. 한국여성 체육학회지, 31: 93-108, 2017.

신승옥, 노은경, 김은삼. 요양보호사의 자기효능감과 삶의 질 관계. 한국엔터테인먼트산업학회논문지, 8: 85-91, 2014. 안미정, 박선주. 미용계열 대학생의 손 씻기 지식과 수행의 관계에서 자기 효능감의 매개효과. 아시안뷰티화장품학술지, 17: 277-286, 2019.

임선희, 김용민. 뷰티산업 종사자와 고객 간의 커뮤니케이션 스타일이 라포르와 고객만족에 미치는 영향. 예술인문사회 융 합 멀티미디어 논문지, 6: 383-395, 2016.

오현옥. 필라테스 리포머 운동의 재미요인이 자기효능감, 지속의도에 미치는 영향. 한국체육과학회지, 28: 209-224, 2019.

윤태진, 김량영, 심상신. 스노볼드 참가자의 재미요인이 심리적 행복감 및 삶의 질에 미치는 영향. 한국웰니스학회지, 6 : 13-23, 2011.

이영주. 미용산업 종사자의 업무환경에 관한 연구: 헤어 업체 종사자들의 삶의 질을 중심으로. 대한미용학회지, 13: 173182, 2017.

이유찬. 주부들의 댄스스포츠 참여 재미요인이 심리적 웰빙 및 감성지능에 미치는 영향. 한국체육학회지, 69: 295-307, 2017.

이유림. 뷰티종사자의 긍정심리자본과 직무스트레스의 상관관계연구. 한국인체미용예술학회지, 21: 31-45, 2020.

이창호. 대학생들의 교양 체육 수업 참여에 따른 재미요인과 신체적 자기 효능감에 미치는 영향. 한국스포츠학회지, 17:689-697, 2019

최희정, 유장학. 농촌지역 독거노인의 우울과 자기 효능감이 건강증진행위에 미치는 영향. 동서간호학연구지, 17: 149$155,2011$.

한만석, 김영삼. 20-50대 여성의 이미지 인식과 헤어 이미지 연출에 따른 자기효능감. 아시아뷰티화장품학술지, 17: 511-520, 2019. 


\section{中文摘要}

\section{乐趣因素对发型设计师自我效能和生活质量的影响}

李永助

敬仁女子大学美发美容学科，仁川，韩国

目的: 这项研究的目的是确定发型设计师的乐趣因素，以使他们从繁重的工作中恢复自我损失感，并将其作为提 高自我效能和生活质量以及个人能力的基本数据。方法: 从2020年7月1日至7月21日, 对首尔和京畿道的美容服 务工作者进行了为期三周的调查, 总共使用了344份进行分析。使用SPSS 26.0程序作为分析方法, 并执行了频 率分析, 因子分析, 可靠性分析, 相关性分析, 单向方差分析, 后测和多元回归分析。结果: 首先, 根据年龄分 析娱乐因素的结果是, 在50岁或50岁以上的人高于 20 岁, 30 岁和 40 岁的人, 并且在娱乐, 社交和健康方面存在 统计学差异。其次, 发型设计师的娱乐因素对自我效能感和生活质量的影响显示出统计学上的正 (+) 相关性, 而生活质量的心理健康状况则具有负 (-) 相关性。第三, 乐趣因素对自我效能的影响在愉悦, 健康和自我效能 方面显示出统计学上显着的正 (+) 相关性。第四, 自我效能感对生活质量的影响在身体健康和能力方面显示出 统计学上显着的正 (+) 相关性。结论: 进行这项研究的目的是建立发型设计师对生活质量的自我效能感, 而发 型设计师年龄越大, 其有趣因素就越有趣。乐趣因素的享受和健康影响着身体的健康和能力, 其结果有助于改 善生活质量。

关键词: 发型设计师，娱乐因素，自我效能感，生活质量，自我满足 
